\title{
DESIGNING RESEARCH TO TRACK SOCIO-PRAGMATIC SKILLS AMONG PROFESSIONALLY QUALIFIED WORKERS ${ }^{1}$
}

\section{Janet Holmes, Meredith Marra, Jonathan Newton, Angela Joe, Nicky Riddiford \& Bernadette Vine}

\author{
Victoria University of Wellington
}

\section{Introduction}

This paper outlines the rationale and design for a research project devised by the authors, all members of the Language in the Workplace (LWP) Project based at Victoria University of Wellington, to track the linguistic progress of a group of skilled migrants from their enrolment in a communication skills course to the end of their internships in a New Zealand workplace.

Conceptualised within a broadly intercultural framework (Kotthoff \& SpencerOatey, 2007), the research is concerned with the development of the migrants' sociopragmatic skills during this period, and pays particular attention to the ways in which the skilled migrants handle the tension between their desire to "fit in" and obtain secure employment, and their need to assert their expertise and construct a professional identity in a new environment. Often these two desires are at odds: fitting in requires adapting to the new culture and its sociolinguistic and communicative norms, and this is often best achieved, at least initially, by taking a background role, quietly observing and responding to rather than initiating interaction. Constructing oneself as an expert, on the other hand often requires relatively assertive and forceful behaviour, at least in some contexts. Balancing these conflicting needs is often a challenge for new migrants, but it has rarely been explicitly identified. ${ }^{2}$ This research thus extends the focus of ESP needs analysis to encompass the challenge of negotiating professional identity in a workplace where one is a minority ethnic group member.

Our approach incorporates a critical component, reflecting our awareness of "connections between workplace uses of language and relations of power at the institutional and broader social levels" (Pennycook, 2001, p.19). The communication skills course aims to empower professional migrant learners to undertake their own analyses of what is going on in workplace interactions (Benesch, 1996; Byram, 1997, 2006a, 2006b; Roberts, Byram, Jordan \& Street, 2001; Newton, 2006; Holmes, Joe, Marra, Newton, Riddiford \& Vine, forthcoming). The research is designed to identify evidence that these skills have been acquired and are being used during the migrants' internships.

People seeking work in a country which uses an international language which is not their mother tongue are undoubtedly at some disadvantage. In such a context, even 
well-educated, skilled migrants may experience the effects of the social inequalities and power disadvantages resulting from their cultural and linguistic difference from the dominant majority (Meeuwis \& Sarangi, 1994; Pennycook, 2001; Rampton, 2001; Blommaert, 2004). The research plan thus incorporates techniques designed to elicit potential employers' attitudes to immigrant workers (cf Derwing \& Krahn, 2008), and their expressed perceptions of their employees' communicative needs. Our longer term goal entails using this research as the basis for materials designed for the New Zealand workplace, and aimed at developing in New Zealanders an appreciation of the richness of the communicative and cultural resources which skilled migrants bring to the New Zealand workplace.

\section{The VUW Workplace Communication Skills course for Professional Migrants}

In 2005, Victoria University of Wellington was contracted to provide languagefocused training courses for skilled migrants who had been unable to find work in their chosen professions in New Zealand for at least two years. The twelve-week course begins with a five-week in-class component followed by a six-week workplace placement or internship (with each Monday afternoon spent back in class), and concludes with a final week in class. The course aims to assist skilled migrants to develop communication skills which will facilitate their attempts to gain employment within their chosen profession in New Zealand. These professions include accountancy, law, teaching, information technology, and medicine. One goal of the initial five week block is therefore to develop awareness of characteristic features of communication in New Zealand workplaces. ${ }^{3}$

In order to enrol in the course, professional migrants are required to be reasonably proficient in English (e.g., IELTS 6.5), and, of course, they are all qualified and experienced experts in their professional areas. Their control of the transactional (task-oriented) aspects of workplace talk is generally adequate: they know how to do the job and they know much of the technical language associated with doing it. And, while pronunciation is sometimes a barrier to comprehension, it is the relational (people-oriented) aspects of workplace interaction which are often particularly challenging, i.e., establishing and maintaining rapport with colleagues. Employers frequently identify relational talk, in particular, as a problem area (e.g., Podsiadlowski, 2006; Clyne, 1994; Spoonley, 2006/2007). Some comment that many workers have all the skills necessary to do the job, and generally cope well with the transactional (information-oriented) aspects of workplace talk, but that they seem unfriendly or uncomfortable at work; they don't seem to fit in smoothly. The reasons for these impressions can generally be traced to problems with handling the sociocultural or relational aspects of communication, and with the acquisition of intercultural competence, rather than more narrowly defined proficiency in English (Brown, 2000; Liddicoat, 2009). 
The analyses undertaken by the LWP Project team have provided a good deal of information about the communicative skills underlying effective relational talk, as well as an extensive corpus of authentic interactions which have been used in developing appropriate classroom materials. ${ }^{4}$ Drawing on this research, the Workplace Communication Skills course aims to provide the well-educated migrants with the ability to analyse workplace interactions along socio-pragmatic dimensions (cf Byram, 1997). The incorporation of an empowering critical dimension helps prepare learners for encounters beyond those presented in class, and encourages them to see their role not as imitators of native speakers, but as social actors engaging with other social actors in a particular kind of communication and interaction which is different from that between native speakers, and which expresses their professional identity in a way they find satisfactory and satisfying.

The materials used in the course are also, importantly, developed from authentic interactions in New Zealand workplaces. Bardovi-Harlig (2001) observes that one cause of non-target like pragmatics is misleading input in teaching materials. She maintains that providing authentic language input is crucial in classroom instruction, a form of "fair play, giving the learners a fighting chance" (2001, p. 30). They provide a means of assisting migrants to become more informed, sensitive, flexible, and strategically equipped communicators in their second language (Tomlinson \& Masuhara, 2004, p. 7).

\section{Working with employers}

Our LWP research has a well-established record of working on "real world" issues identified in collaboration with "real world" partners (Bygate, 2004, p. 18). We have consistently worked with practitioners to identify issues of mutual interest, drawing on our knowledge of the way language works, and especially our awareness of the immensely important influence of contextual factors on communication in researching those issues. Basing our design as far as possible on the action research principle of research "for and with" our participants (Cameron, Frazer, Harvey, Rampton, \& Richardson, 1992, p. 22), we have aimed for a research process which is as open and empowering as possible, and which avoids exploitation of those we work with.

Working with professional migrants seeking employment in a diverse range of specialities has involved canvassing the views of a wide range of potential employers. While we have some general information from employers about what they see as the disadvantages and the reasons for not employing migrant workers (Henderson, 2007; Podsiadlowski, 2007), there is little specific information from particular professional areas. The hundred employers that Astrid Podsiadlowski interviewed identified language proficiency, communication difficulties, and cultural differences (including different attitudes to work) as the chief disadvantages of employing migrants. But the experience and observations of our workplace mentors and support people suggests that a more fundamental issue is often the attitudes and 
expectation of the employers towards their employees. Some employers are very positive in their approach, seeing migrants as providing valuable cultural resources, a source of fresh opinions, different ways of thinking, and alternative approaches to evaluation. Other potential employers, however, regard migrant workers through yellow-tinted (i.e., jaundiced) spectacles, categorise them as a "perceived risk", and do not appreciate what they offer.

Consequently, the project outlined below involves a fundamentally collaborative methodology in order (a) to systematically document changes, if any, in professional migrant learners' ability to manage workplace interaction, including their ability to undertake their own analyses of what is going on, and to actively construct a satisfying professional identity, and (b) to investigate the contribution of employers' expectations and attitudes to the extent of learners' workplace communicative success, and to identify changes, if any, over the placement period. This approach provides opportunities for self-reflexive techniques combined with direct engagement with issues of relevance to the wider community (Roberts, 2003; Candlin \& Sarangi, 2004; Sarangi, 2006, p. 215), as well as facilitating a productive, collaborative partnership between researchers and researched (Sarangi, 2006, p. 215).

\section{The research plan}

The steps in the proposed research project:

\section{A. Stage 1: Interview data}

(i) Discussion with course participants to establish

a. how they perceive their communicative needs

b. what they expect from the course

c. how we can work collaboratively to attain their goals

This step addresses the challenge of communicating to participants the importance of developing not only their analytical skills but also of acquiring ways of expressing different communicative strategies which are comfortable for them and which index the kind of professional identity they wish to enact.

(ii) Discussion with employers to establish

a. how they perceive employees' communicative needs

b. what they expect from the course

c. how we can work collaboratively to attain their goals

Potential employers will first be identified according to the professional backgrounds of the course participants. Each course participant's work profile, together with a description of the placement process, and of the content of the communication skills course, will then be circulated to the list of potential employers. Willing employers will be interviewed to establish their expectations of employees, their attitudes 
towards EAL users, and their expectations of what the course will provide for the employees.

(iii) Discussion with workplace support people

a. how they perceive employees' communicative needs

b. what they expect from the course

c. how we can work collaboratively to attain their goals

Each employee will be provided with an internal support person or mentor from within the organisation in which they have been placed. In addition, one of our research team will act as a workplace consultant providing further support throughout the internship period, and liaising regularly with the workplace mentor as well as the intern. Workplace mentors will be interviewed at the start of the internship to establish their expectations of their intern, their attitudes towards EAL users, and their expectations of what the course will provide for the intern.

\section{B. Stage 2: Recorded data}

(i) Collect recorded data to establish workplace interactional norms

Our data collection method has been thoroughly described elsewhere (Holmes \& Stubbe, 2003). Its most distinctive feature is the fact that the participants themselves record their everyday workplace talk with as little interference from the research team as possible. As far as possible, our policy is to minimise our intrusion as researchers into the work environment, while also carefully managing ethical matters and confidentiality. After the recordings are obtained, the material is processed, selected sections are transcribed, and useful and useable material for instruction is selected for analysis (Holmes \& Stubbe, 2003; Marra, 2008).

(ii) Collect recorded data on participants' proficiency in selected areas (small talk, requests) at start and end of course

As part of the normal processes involved in participating in the course, information will be gathered at the beginning and end of the course on participants' spoken proficiency and ability to accurately interpret socio-pragmatic aspects of workplace talk, with a focus on requests and small talk (Riddiford, 2007).

(iii) Collect data from participants in workplace at start and end of placement. The standard LWP methodology will be used for this, as described in (i) above

\section{Stage 3: Interview data}

Discussion with (i) course participants and (ii) employers to establish whether, and if so to what extent, they feel that the course has met their needs, and to gather their reflections on what they have learned. 
(iii) Discussion with workplace mentors to collect their views on the participants' progress in communicating effectively at work, and to gather their reflections on what they have learned. Their views will also be sought regarding any perceived changes in attitudes towards the course participant by other employees and the employer.

\section{Discussion}

This paper has outlined the rationale and structure of a project aimed at tracking the progress of professional migrants from the point at which they enrol in a communications skills course through to their total engagement in workplace interaction. Rather than simply shoe-horning migrants into employment, the project aims to empower learners to make choices about the kind of identity they want to construct in workplaces where their expertise is valued (Spreckels \& Kotthoff, 2007). The Workplace Communication Skills course provides analytical skills which enable migrants to select linguistic forms which enact an authoritative identity when required, and to be supportive, collaborative and collegial when they judge it appropriate.

Socio-cultural, sociolinguistic and socio-pragmatic differences are undoubtedly sources of potential miscommunication in New Zealand workplaces. New Zealand has a very high level of monolingualism (Starks, 1998), and many Pākehā people are rather suspicious of those from different cultural backgrounds. There is clearly an opportunity for applied linguists to provide information which might assist in changing attitudes so that migrants' linguistic and cultural resources are more widely viewed positively, as assets rather than drawbacks.

Many Pākehā are simply unaware of the stresses that people from different cultures face on a daily basis because of different expectations about "normal" ways of behaving at work, or about what is considered an acceptable way of communicating. The situation of new migrants is particularly challenging since they are generally working in isolation from other members of their linguistic and cultural group. They have no obvious source of tension relief or camaraderie with others in the same minority situation. However, developing an understanding of the migrants' situation among co-workers could provide a starting point for humour and social talk which would contribute both to the development of camaraderie and to the empowerment of the migrant professional. The planned research is designed to provide information which could inform such an approach.

\section{Conclusion}

This paper has outlined a research project, conceptualised within a broadly intercultural framework, aimed at evaluating the success of a communication skills course in empowering skilled migrants as they enter the New Zealand workforce. The project will gather data on the effects of a communication skills course on migrants' socio-pragmatic proficiency and analytical abilities; it will also collect information on 
employer attitudes towards their migrant employees, with the long-term goal of providing information to assist employers and co-workers in understanding and appreciating the distinctive socio-cultural backgrounds and different socio-pragmatic norms of migrant employees. This comprises another less direct means of empowering learners; more positive and supportive attitudes will potentially liberate migrants to exercise their expertise more fully.

This project will be the first of which we are aware to record authentic workplace talk in order to examine the effects for professional migrants of participation in a course which explicitly focuses on the development of socio-pragmatic and analytical skills in workplace interaction. It will also be the first to work with employers with the aim of raising their awareness of the positive attributes of migrant professional workplaces and of the ways in which the diverse cultural and linguistic resources they bring to a community of practice can enhance the quality of workplace interaction.

\section{Notes}

1 This paper was presented in March 2008 at a Symposium ("New Directions for Applied Linguistics: Discourse Analysis in Applied Linguistics: what does the future hold?"), organised by Chris Candlin and Ron Carter at AAAL in Washington DC. We express our appreciation to our copresenters and the audience who contributed to a valuable discussion of the issues raised in the paper.

${ }^{2}$ But see Campbell and Roberts (2007), Roberts et al. (2008).

${ }^{3}$ See Riddiford and Joe (2005), Newton (2007) and Prebble (2007) for more information about the course.

${ }^{4}$ See, for example, Holmes (2005a, 2005b) on small talk, Holmes and Marra (2002, 2006) on humour, Vine (2004) on diverse ways of giving directives and making requests, and Daly et al (2004) on refusals and complaints in different communities of practice.

\section{References}

Bardovi-Harlig, K. (2001). Evaluating the empirical evidence: Grounds for instruction in pragmatics? In K. Rose, \& G. Kasper (Eds.), Pragmatics in language teaching (pp 13-32). Cambridge: Cambridge University Press.

Benesch, S. (1996). Needs analysis and curriculum development in EAP: An example of a critical approach. TESOL Quarterly, 30(4), 723-738.

Blommaert, J. (2004). Discourse: A critical introduction. New York: Cambridge University Press.

Brown, P. (2000). Directives in a New Zealand factory. Unpublished M.A. Thesis. Victoria University of Wellington, New Zealand.

Byram, M. (1997). Teaching and assessing intercultural communicative competence. Clevedon: Multilingual Matters.

Campbell, S. \& Roberts, C. (2006). Migration, ethnicity and competing discourses in the job interview: Synthesising the institutional and the personal. Discourse and Society, 18(3), 243-71.

Cameron, D., Frazer, E., Harvey, P., Rampton, M.B.H \& Richardson, K (1992). Researching language: Issues of power and method. London; New York: Routledge.

Clyne, M. (1994). Inter-cultural communication at work: Cultural values in discourse. Cambridge: Cambridge University Press. 
Daly, N., Holmes, J., Newton, J. \& Stubbe, M. (2004). Expletives as solidarity signals in FTAs on the factory floor. Journal of Pragmatics, 36(5), 945-964.

Derwing, T.M. \& Krahn, H. (2008). Attracting and retaining immigrants outside the metropolis: Is the pie too small for everyone to have a piece? The case of Edmonton. Journal of International Migration and Integration, 9, 185-202.

Henderson, A. (2007). English language proficiency and the employment of professional immigrants in New Zealand: How much is enough? CACR Newsletter, 2. Retrieved October 2008 from http://www.victoria.ac.nz/cacr/news-events/newsletter2.aspx

Holmes, J. (2005a). Relational and transactional functions of workplace discourse: A sociopragmatic perspective. In B-L. Gunnarson (Ed.), Communication in the workplace (pp. 7-27). Uppsala: Universiteitstrysckeriet Ekonimikum.

Holmes, J. (2005b). When small talk is a big deal: Sociolinguistic challenges in the workplace. In M.H. Long (Ed.), Second language needs analysis (pp. 344-371). Cambridge: Cambridge University Press.

Holmes, J. \& Marra, M. (2002). Having a laugh at work: How humour contributes to workplace culture. Journal of Pragmatics, 34(12), 1683-1710.

Holmes, J., Joe, A., Marra, M., Newton, J., Riddiford, N. \& Vine, B. (forthcoming). Applying linguistic research to real world problems: The case of the Wellington Language in the Workplace Project. To appear in C. Candlin, \& S. Sarangi (Eds.), Handbook in applied linguistics. Berlin: Mouton de Gruyter.

Holmes J. \& Marra, M. (2006). Humor and leadership style. Humor, 19(2), 119-38.

Holmes, J. \& Stubbe, M. (2003). Power and politeness in the workplace: A sociolinguistic analysis of talk at work. London: Longman.

Kotthoff, H \& Spencer-Oatey, H. (Eds.). (2007). Handbook of intercultural communication. Berlin: Mouton de Gruyter.

Liddicoat, A.J. (2009). Communication as culturally contexted practice: A view from intercultural communication. Australian Journal of Linguistics, 29(1), 115-133.

Marra, M. (2008). Recording and analyzing talk across cultures. In Spencer-Oatey, H. (Ed.), Culturally speaking: Culture, communication and politeness theory (2nd ed.) (pp. 304-321). London; New York: Continuum.

Newton, J. (2007). Adapting authentic workplace talk for workplace communication training. In H. Kotthoff, \& H. Spencer-Oatey (Eds.), Handbook of intercultural communication (pp. 519535). Berlin: Mouton de Gruyter.

Pennycook, A. (2001). Critical applied linguistics: A critical introduction. Mahwah, NJ: Lawrence Erlbaum.

Podsiadlowski, A. (2006). Facilitating migrants' entry and integration into the New Zealand workplace: Summaries of completed research. Online article. Retrieved October 2008, from http://www.victoria.ac.nz/cacr/research/migrantentry-com.aspx

Podsiadlowski, A. (2006). (Ed.). Building a culturally diverse workforce in Aotearoa/New Zealand. CACR Newsletter, 2. Online article. Retrieved April 2007 from: http://www.victoria.ac.nz/ cacr/news-events/newsletter2.aspx

Prebble, J. (2007). Workplace communication for skilled migrants: English for professional purposes. Victoria University of Wellington, New Zealand Online article. Retrieved October 2008 from http://www.victoria.ac.nz/lals/programmes/english-prof/Skilled\%20MigrantsCourse $\% 20$ Description.aspx

Rampton, B. (2001). Language crossing, cross-talk and cross-disciplinarity in sociolinguistics. In N. Coupland, S. Sarangi, \& C.N. Candlin (Eds.), Sociolinguistics and social theory (pp. 261296). London: Pearson Education Limited.

Riddiford, N. (2007). Making requests appropriately in a second language: Does instruction help to develop pragmatic proficiency? The TESOLANZ Journal, 15, 88-102.

Riddiford, N. \& Joe, A. (2005). Using authentic data in a workplace communication programme. New Zealand Studies in Applied Linguistics, 11(2), 103-110. 
Roberts, C. (2003). Applied linguistics applied. In S Sarangi, \& T. van Leeuwen (Eds.), Applied linguistics and communities of practice (pp. 132-149). London: Continuum.

Roberts, C., Byram, M., Jordan, A.B.S. \& Street, B. (2001). Language learners as ethnographers. Buffalo, NY: Multilingual Matters.

Roberts, C., Campbell, S. \& Robinson, Y. (2008). Talking like a manager: Promotion interviews, language and ethnicity. Research Report No 510. Department for Work and Pensions online article. Retrieved 30 September 2008 from http://www.dwp.gov.uk/asd/asd5/rports20072008/rrep510.pdf

Sarangi, S. (2006). The conditions and consequences of professional discourse studies. In R. Kiely, P. Rea-Dickens, H. Woodfield \& G. Clibbon (Eds.), Language, culture and identity in Applied Linguistics (pp. 199-220). London: Equinox.

Spoonley, P. (2006/2007). Immigrants face employment discrimination. Human Resources, December 2006/January 2007, 27-27.

Spreckels, J. \& Kotthoff, H. (2007). Communicating identity in intercultural communication. In H. Kotthoff, \& H. Spencer-Oatey (Eds.), Handbook of intercultural communication (pp. 415439). Berlin: Mouton de Gruyter.

Starks, D. (1998). Monolingual speakers of New Zealand's languages. New Zealand Studies in Applied Linguistics, 4, 71-75.

Tomlinson, B. \& Matsuhara, H. (2004). Developing cultural awareness: Integrating culture into a language course. Modern English Teacher, 13(1), 1-7.

Vine, B. (2004). Getting things done at work: The discourse of power in workplace interaction. Amsterdam: John Benjamins. 